\title{
Socioeconomic Development: Search For Optimal Models For Forecasting Inflationary Processes
}

\author{
Mikhail Samuilovich Gasparian*, Irina Anatolievna Kiseleva, Valeriy Aleksandrovich Titov, \\ Nikita Aleksandrovich Sysoev and Elena Nikolaevna Chernysheva
}

\begin{abstract}
Plekhanov Russian University of Economics, Moscow, Russia
Abstract: The article is devoted to the analysis of the forecasting models for inflationary processes. The monetarist approach to inflation has been discussed in the article, and the inflation forecasting tools have been classified. Various inflation forecasting models have been studied, namely, one-factor models, Phillips-curve-motivated forecasts, vector autoregressive models, and dynamic models of general equilibrium. Comparative characteristics of the quality of the inflation forecasting models have been provided.
\end{abstract}

Keywords: Inflation, inflation forecasting, models, risks.

\section{INTRODUCTION}

Inflation is a fairly common process, especially in the modern world. In simple terms, inflation is the depreciation of money. A more precise definition is the increase in prices for various goods and services over a long period. Inflation also influences real purchasing power. A different amount of goods can be purchased for the same amount of money in different years (Kolmykova 2012; Nasakina 2011; Savitskaya 2014).

Inflation in the market economy is manifested in a direct increase in the price of goods. It can take a slightly different form during the administrative intervention in the economy: there is no price increase, but there is a shortage of goods.

Inflation can have both positive and negative impacts on the economy. It has a stimulating effect on commodity circulation, serves as a factor in the natural selection of economic evolution, and contributes to the growth of the competitiveness of domestic goods. The state with a progressive tax system can obtain additional income from inflation (Volkov, 2012; Nikitin 1995; Illarionov 1995).

Inflation accelerated to $3.1 \%$ in April 2020 compared to April 2019 and $0.8 \%$ compared to March 2020, according to the Federal State Statistics Service. Annual inflation amounted to $2.5 \%$ in March, $2.3 \%$ in February, and $2.4 \%$ in January. Consumer prices rose by $2.6 \%$ in January - April compared to the same period in the previous year. Prices for food products rose by $1.7 \%$ in April compared to March 2020, where prices for food products net of fruits and vegetables

*Address correspondence to this author at the Stremyanny lane, 36, Moscow, 117997, Russia; Tel: + 7 (495) 958-21-56; E-mail: mikhail_gasparian@mail.ru rose by $0.9 \%$. Prices for non-food products rose by 0.4 $\%$ in April compared to the previous month, and prices for services rose by $0.1 \%$ (Starostina, 2020).

Reasons for the appearance of inflation are as follows:

- $\quad$ Continuous currency emission to cover various expenses (mainly government spending);

- Monopolies. This allows monopolists to set their prices for goods and services, thereby covering their production costs;

- Reduction in the real volume of national output, which leads to an increase in prices at a stable level of money supply, because a smaller amount of goods and services corresponds to the previous amount of money; and

- Increase and introduction of new state taxes, duties, excise taxes, etc., at a stable level of money supply (llyashenko, and Kuklina 2017; Lambin 1996; Foss 2007).

The observed increase in inflation expectations is determined by temporary inflationary factors, including a drop in oil prices. However, their change will be shortterm in conditions of decreasing demand. According to the forecast of the Bank of Russia, annual inflation will amount to $3.8-4.8 \%$ following the results of 2020 and will stabilize near $4 \%$ in the future, taking the current monetary policy into account (CBR 2020).

\section{LITERATURE REVIEW}

The founder of monetarism is the representative of the Chicago school Milton Friedman (2002), a 1976 Nobel Prize winner in Economics. K. Brunner, Ph. 
Cagan, A. Meltzer, D. Laidler, and M. Parkin are the most prominent representatives of the school of monetarism (Bogoviz et al., 2019; Illarionov, 1995; Thompson, 2009).

In monetarism, it is believed that the appearance of inflation is caused mainly by the financial policy of the state. The monetarist approach is that the markets are sufficiently competitive and the market competition system secures a high degree of macroeconomic stability. As such, if not subjected to government intervention in the economy functioning, the market system secures significant macroeconomic stability (Snowdon, and Vane 2002).

Monetarists adhere to the neoclassical position that the economy always functions in a state of full employment in the long run. Therefore, a change in the money supply does not affect the real economy in the long run, i.e., does not affect the real interest rate or level of investment and employment, and leads to an adequate change in prices.

Monetarists believe that economic growth can be determined exogenously, it does not completely depend on the growth rate of the money supply, while the money velocity is relatively stable. Therefore, when taking into account the equation of exchange

$\mathrm{MV}=\mathrm{PV}$

(where $\mathrm{M}$ is the nominal money supply, $\mathrm{V}$ is the money velocity, $P$ is the price level, and $Q$ is the volume of output), inflation is equal to the growth rate of the money supply.

Monetarists usually propose the so-called "tight monetary policy" to fight inflation. Its main task is to reduce the amount of money in circulation or to slow down the money velocity. Several events can lead to this result:

1. Increased tax burden,

2. Reduced or frozen wages,

3. Lower budget spending, and

4. Reduced lending.

Inflation can be classified by:

1. Nature of the manifestation:
a. Open
b. Suppressed

2. Growth rate:
a. Creeping
b. Galloping
c. Hyperinflation

3. Level of aggregation

Inflation is measured using various indices:

- $\quad$ consumer price index $(\mathrm{CPI})$,

- $\quad$ producer price index,

- $\quad$ cost-of-living index,

- $\quad$ asset price index,

- GDP deflator,

- $\quad$ purchasing power parity,

- $\quad$ online store price index, and

- $\quad$ average check indices.

Modeling inflation and its further forecasting is one of the most important tasks of the state regarding inflation. It can be done using the following models: Friedman model, Cagan model, Bruno-Fischer model, and Sargent-Wallace model (Kolmykova, 2012; Volkov 2015; Volkov, 2012; Chernyshova, 2014; Eliferov, Repin, 2013; Snowdon, Vane, 2002).

\section{METHODOLOGY}

\subsection{Selection of Inflation Forecasting Tools}

The following groups of forecasting methods can be used to predict the dynamics of prices during inflation:

- $\quad$ Surveys

- Mathematical methods and

- $\quad$ Modeling based on expert judgment.

Mathematical models are a very large class of methods used to build models and forecast, consisting of several subgroups:

- One-factor models,

- $\quad$ Use of trends (GDP deflators, CPI),

- Models of autoregression, moving average, ARIMA,

- Multifactor models,

- $\quad$ Appeared in the 1960s, and 
- $\quad$ Modeling the inflation process based on expertly selected variables.

Many models have appeared over the entire existence of mathematical modeling, which is constantly being modified and refined (Ol'derogge et al. 2014; Volkov 2015; Gromov et al. 2007; Kiseleva et al. 2019). For example, the following models are in the greatest demand among the 20 types:

- $\quad$ Phillips-curve-motivated forecast,

- Vector autoregressive models (VAR),

- Dynamic stochastic general equilibrium models (DSGE), and

- $\quad$ Models using neural networks.

All classes of mathematical models for forecasting inflationary processes are based on the use of mathematical formulas and properties to increase the accuracy of the model, and therefore the accuracy of the prediction. The inflation gap indicator is one of the most striking examples. This indicator shows the gap or difference between actual prices and equilibrium prices for a given situation.

Another, no less popular way to increase the accuracy of modeling is to test the model on sufficiently large data samples. This allows not only to select the model coefficients with greater accuracy but also to check the significance of each of the factors included in the original model.

\section{ONE-FACTOR INFLATION FORECASTING MODELS}

It makes sense to use one-factor models for small periods or when the accuracy or details of the model are not critical. The main advantages of one-factor models are the following:

- $\quad$ They are easy to build,

- They can be easily adjusted,

- $\quad$ These models are easy to understand, as are the results obtained after building and forecasting, and

- $\quad$ The result can easily be interpreted.

\subsection{The Most Common One-Factor models}

"Random walk" models. Random walk models allow analyzing processes devoid of trends, seasonality, and other patterns. A variation of Atkeson and Ohanian is used in the modeling:

$$
\pi_{t+h}=\frac{1}{4} \sum_{i=1}^{4} \pi_{t+1-i}+\varepsilon_{t+h}
$$

where $\pi t$ is the inflation rate in period $t ; h$ is the planning horizon and $\varepsilon t+h$ is the random error.

Direct autoregression models. DAR models are as follows:

$$
\pi_{t+h}=a+\sum_{i=1}^{p} b_{i} * \pi_{t-i}+\varepsilon_{t+h}
$$

where $\pi t$ is the inflation rate in period $t ; a, b$ are the coefficients for variables; $h$ is the planning horizon, and $\varepsilon t+h$ is the random error.

Recursive autoregression models (RAR):

$$
\pi_{t}=a+\sum_{i=1}^{p} b_{i} * \pi_{t-i}+\varepsilon_{t}
$$

where $\pi t$ is the inflation rate in period $t ; a, b$ are the coefficients for variables; and $\varepsilon t+h$ is the random error.

ARIMA models:

$$
\left(\Delta^{d} \pi_{t}\right)=a+\sum_{i=1}^{p} b_{i} * \Delta^{d} \pi_{t-i}+\sum_{j=1}^{q} c_{j} * \Delta^{d} \varepsilon_{t-j}+\varepsilon_{t}
$$

where $p$ is the order of autoregression; $q$ is the order of the moving average; $d$ is the order of difference; $\pi t$ is the inflation rate in period $t ; \alpha, b$ are the coefficients for variables; and $\varepsilon t+h$ is the random error.

\subsection{Phillips-Curve-Motivated Forecast}

The idea that inflation and unemployment were related turned out to be unstable during long periods of modeling. This is because all economic agents have their expectations, which greatly influence their behavior.

Due to this remark, a "triangular" model appeared, where the inflation rate depends on three variables:

- Unemployment rate,

- The shock of costs, and

- Previous inflation rate

$$
\pi_{t}=a+b \pi_{t-L}+c u_{t-L}+d z_{t-L}+\varepsilon_{t}
$$

where:

- $\pi t$ is the inflation rate in period $t$, 
- $\quad a, b, c, d$ are the coefficients for variables,

- ut is the unemployment rate,

- $\quad$ it is the variable describing the supply shock,

- $\quad \mathrm{L}$ is the lag value, and

- $\varepsilon t$ is the random error.

This model was improved after successful tests, during which all variables were clearly expressed. Namely, dummy variables that described the state policy in the field of wage regulation and real purchasing opportunities were added.

\subsection{Vector Autoregressive Models}

The VAR models have been actively used since 1992. The general view of the VAR models is as follows:

$\left\{Y_{1 t}=a_{1}+b_{1} Y_{1 t-1}+c_{1} Y_{2 t-1}+d_{1} X_{1 t-1}+e_{1} X_{2 t-1}+\varepsilon_{1 t}\right.$

$\left\{Y_{2 t}=a_{2}+b_{2} Y_{1 t-1}+c_{2} Y_{2 t-1}+d_{2} X_{1 t-1}+e_{2} X_{2 t-1}+\varepsilon_{2 t}\right.$

where:

- $\quad$ Y1t, Y2t are the endogenous variables,

- $\mathrm{X} 1 \mathrm{t}, \mathrm{X} 2 \mathrm{t}$ are the exogenous variables,

- $\quad$ a, b, c, d, e are the coefficients for variables, and

- $\quad \varepsilon 1 \mathrm{t}, \varepsilon 2 \mathrm{t}$ is the random errors.

It was concluded through the study and application of the VAR that prices increased along with an increase in the interest rate. This was the so-called "price paradox" that arose due to the existence of a missing factor in the VAR model. It later turned out that this factor was a change in the interest rate.

\subsection{B. Bernanke's Inflation Model}

Another well-known inflation model was proposed by $\mathrm{B}$. Bernanke. It is a factor-expanded VAR model that allows using about 120 factors, which can be combined into the following groups:

- $\quad$ output and income,

- employment,

- consumption,

- permits for the construction and sale of real estate,

- $\quad$ stocks and orders,
- $\quad$ stock indices,

- exchange rates,

- interest rates,

- $\quad$ monetary and credit aggregates,

- $\quad$ price indices, and

- $\quad$ average salary

This model also allowed to get rid of the "price paradox" due to the peculiarities of the interaction between the exogenous and endogenous variables.

One of the biggest advantages of the VAR models is the lack of restrictions on a wide range of specifications:

- Economics,

- Factors

- Interaction between the factors, and

- $\quad$ Economic meaning.

However, these advantages can turn into big disadvantages if the situation and the interaction between the factors are not studied deeply and in sufficient detail. In practice, the high accuracy of the forecast is required in most cases, rather than the observance of all conditions and the precise adjustment of all factors in terms of meaning and economic concepts. The VAR models are popular due to this flexibility.

\section{RESULTS}

All models are usually selected by the criterion of higher accuracy of modeling and forecasting compared to previous models (Table 2).

The use of different selection criteria on different models is a common occurrence. For example, many experts compare several models, which include both their development and third-party models, on their data to study the resulting model. This leads to the emergence of mathematical models that greatly exceed the accuracy of many existing ones (Bogoviz et al. 2019; Thompson 2009; Shapkin and Shapkin 2013).

However, there are minor reservations even in such methods, which can sometimes make it impossible to use the results in the future or other samples.

The process of creating such models usually involves the perfection of the existing modeling 
Table 1: Comparison of the Inflation Forecasting Models

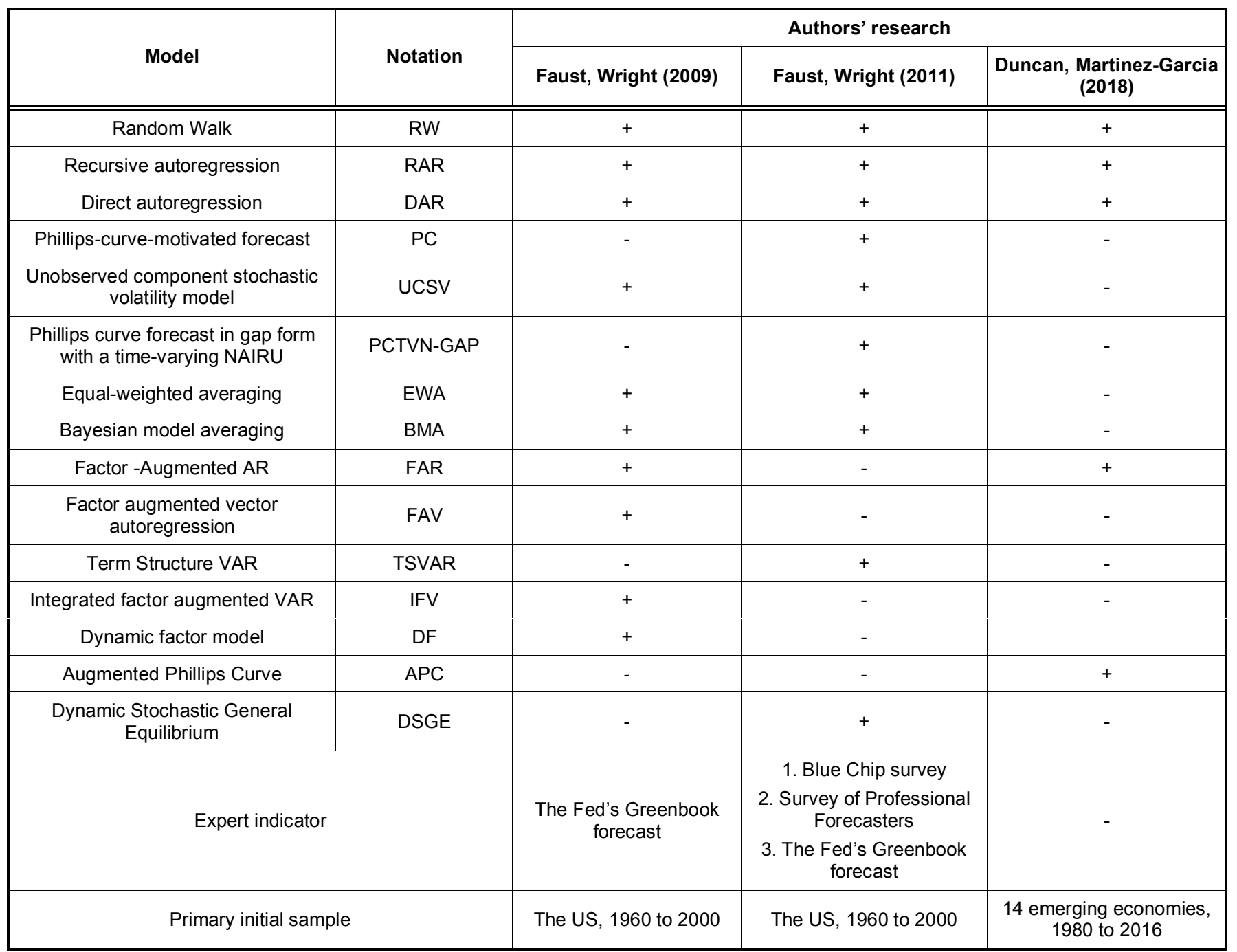

methods and techniques. This is achieved by expanding the number of variables, adding new functionality, etc.

This entails a significant complication of preparing data for processing. As such, all the initial data must be modified in a complex manner, which ceases to be observed over time, according to experience. Such an integrated approach leads to the supply of poor-quality data to the model, which either reduces the accuracy of forecasting or gives completely incorrect results (Morrow et al. 2007; Eliferov, and Repin 2013; Keller 2008).

\section{DISCUSSION}

The synergy of various models, opinions, and forecasts is an equally important way. Using equalweighted averaging and given the weight of the forecasts, or using the Bayesian model averaging method, even more, accurate forecasts can be obtained that will take into account all aspects that influence the inflation rate.

For example, large banks, consulting agencies, and other companies and corporations have long been using a peculiar synthesis of a fairly large number of models. They can take anything into account: from prices for goods and services to the global news (Table 2).

The experience of the world powers testifies to the efficiency of the inflation targeting policy. However, it is still in its infancy and developing in Russia, unlike in developed countries. Therefore, it is too early to talk about its results. As such, inflation remains one of the most acute economic problems of modern Russia, which requires careful study and analysis. The further prosperity of Russia and its competitiveness at the global level depends on how fast, high-quality, and 
Table 2: Basic Models of Economic Analysis Used by Central Banks

\begin{tabular}{|c|c|}
\hline Central bank & Basic model \\
\hline \hline US Federal Reserve Bank & New Keynesian DSGE model of a "large" open economy \\
\hline European Central Bank & New Keynesian DSGE model of a "large" open economy \\
\hline Bank of England & New Keynesian DSGE model of a "small" open economy \\
\hline Bank of Sweden & DSGE model of a "small" open economy \\
\hline Bank of Spain & Error correction models (Phillips-curve-motivated forecast) \\
\hline Bank of Denmark & Several models, DSGE being the main of them \\
\hline Bank of Japan & DSGE model of a "small" open economy (inflation forecast is built by combining forecasts from \\
\hline Bank of Russia & various models) \\
\hline
\end{tabular}

efficient the measures of the state policy in this area will be (Chernyshova 2014; Somova 2012).

Inflation in the economy of the Russian Federation was caused by a decrease in the efficiency of social production, had a hidden nature, and was manifested in a shortage of goods and a gap in prices: low for final products and high for raw materials. Russia has seen a decrease in inflation over the past 13 years (Kondrus, and Kozyrkova 2017; Nazirov, Mehdiyev, and Dovletmurzaeva 2016).

The synergy of various models, opinions, and forecasts is the main way. More accurate forecasts can be obtained using equal-weighted averaging, given the weight of forecasts, or using the Bayesian model averaging method, which will account for all the aspects that influence the inflation rate. They can take anything into account: from prices for goods and services to global news.

\section{CONCLUSION}

Many specialists make calculations based on the obtained data to track the level of inflation. The mathematical models for forecasting inflationary processes are based on the use of mathematical formulas and properties to increase the accuracy of the model, and therefore the accuracy of the forecasting.

\section{ACKNOWLEDGEMENTS}

This research was performed in the framework of the state task in the field of scientific activity of the Ministry of Science and Higher Education of the Russian Federation, project "Development of the methodology and a software platform for the construction of digital twins, intellectual analysis and forecast of complex economic systems", grant no. FSSW-2020-0008.

\section{REFERENCES}

Bogoviz, A.V., Osipov, V.S., Chistyakova, M.K. and Borisov, M.Y 2019. "Comparative analysis of formation of industry 4.0 in developed and developing countries". Studies in Systems, Decision and Control 169:155-164. https://doi.org/10.1007/978-3-319-94310-7 15

CBR. 2020. Inflation expectations and consumer sentiment $4(40)$ URL: $\quad$ https://cbr.ru/Collection/Collection/File/27844/ Infl_exp_20-04.pdf

Chernyshova, N.A. 2014. Inflationary processes in Russia: causes results, forecasts. Proceedings of the III International Scientific Conference «Economics, Management, Finance», Perm, Russia, February 20-23, 2014. Perm: Mercury. pp. 2730.

Eliferov, V.G. and Repin, V.V. 2013. Business processes: Regulation and management: Textbook. Moscow: INFRA-M.

Foss, N.J. 2007. "Scientific Progress in Strategic Management: The Case of the Resource-Based View". International Journal of Learning and Intellectual Capital 4(1/2):29-46. https://doi.org/10.1504/IJLIC.2007.013821

Gromov, A.I., Chebotarev, V.G., Gorchakov, Ya.V. and Boyko, O.I 2007. Analysis and modeling of business processes. Moscow: National project "Education", Innovative educational program State University - Higher School of Economics "Formation of a system of analytical competencies for innovation in business and public administration", Department of Modeling and Optimization of Business Processes.

Illarionov, A. 1995. "Nature of Russian inflation". Journal Economic issues 3:4-21.

Ilyashenko, V.V. and Kuklina, L.N. 2017. "Inflation in modern Russia: theoretical foundations, specifics of manifestation and a regional aspect". Regional economy 13(2):434-445. https://doi.org/10.17059/2017-2-9

Keller, K. 2008. Framework for Marketing Management. New Jersey: Pearson Prentice Hall.

Kiseleva, I.A., Gasparian, M.S., Chernysheva, E.N., Voronkova, T.N and Androshina, I.S. 2019. "Peculiarities of Modelling Operation of a Business Venture". International Journal on Emerging Technologies 10(3):318-323.

Kolmykova, T.S. 2012. Investitsionnyy analiz [Investment analysis] Moscow: INFRA-M.

Kondrus, T.A., and Kozyrkova, A.V. 2017. "Features and causes of inflation in modern Russia". Economy Vector 4(10):40. 
Lambin, J.-J. 1996. Marketing Strategy: A New European Approach. St. Petersburg: Nauka.

Morrow, J.L., Sirmon, D.G., Hitt, M.A., Holcomb, T.R. 2007. "Creating Value in the Face of Declining Performance: Firm Strategies and Organizational Recovery". Strategic Management Journal 8(3):271-283. https://doi.org/10.1002/smj.579

Nasakina, L.A. 2011. "Development of accounting and analytical support for sustainable development management of economic agents based on international experience". Economics and Management: New Challenges and Prospects 2:357-359.

Nazirov, D.T., Mehdiyev, Sh.R., Dovletmurzaeva, M.A. 2016. Inflationary processes in modern Russia: causes, trends and anti-inflationary policy. Proceedings of the All-Russian scientific and practical conference of students, young scientists and graduate students "Science and Youth». Grozny: Chechen State University, pз. 202-207.

Nikitin, S. 1995. "Inflation and the possibilities of overcoming it". Economist 8:52-61.

Ol'derogge, N.G., Shapiro, V.D., Polkovnikov, A.V., and Mazur, I.I. 2014. Upravleniye proyektami [Project management]. Moscow: Omega-L.
Savitskaya, G.V. 2014. Analysis of the efficiency and risks of entrepreneurial activity: methodological aspects. Moscow: Infra-M.

Shapkin, A.S., Shapkin, V.A. 2013. Economic and financial risks. Assessment, management, investment portfolio. Moscow: Publishing and trading company Dashkov and Co.

Snowdon, B. and Vane, H. 2002. "Modern Macroeconomics and Its Evolution from a Monetarist Perspective: An Interview with Professor Milton Friedman". Ecovest, 2(4):520-557.

Somova, I.A. 2012. "Targeting inflation in Russia: problems and prospects". Bulletin of the NSU. Series: Socioeconomic Sciences 12(2):5-12.

Starostina, Yu. 2020. Rosstat announced acceleration of annual inflation in April to $3.1 \%$. RBK. URL: https://www.rbc.ru/ economics/07/05/2020/5eb43db89a79472e6299595b

Thompson, G.M. 2009. "Revenue Management Forecasting Aggregation Analysis Tool (RMFAA Tool)". Cornell Hospitality Tool 9:1-5.

Volkov, A.V. 2012. Modeling of economic systems and processes Experience of building business models]. Moscow: SUSU.

Volkov, O.N. 2015. Standards and methods for modeling business processes: textbook for universities. Moscow: ASV.

Received on 03-01-2021

Accepted on 28-01-2021

Published on 03-02-2021

DOI: https://doi.org/10.6000/1929-4409.2021.10.55

(c) 2021 Gasparian et al.; Licensee Lifescience Global.

This is an open access article licensed under the terms of the Creative Commons Attribution Non-Commercial License (http://creativecommons.org/licenses/by-nc/3.0/) which permits unrestricted, non-commercial use, distribution and reproduction in any medium, provided the work is properly cited. 